\title{
Impact of Livestock Encroachments and Tree Removal on Populations of Mountain Nyala and Menelik's Bushbuck in Arsi Mountains National Park, Ethiopia
}

\author{
Zerihun Girma $\mathbb{D}^{1},{ }^{1}$ George Chuyong, ${ }^{2}$ and Yosef Mamo $^{3}$ \\ ${ }^{1}$ School of Wildlife and Eco-Tourism, Hawassa University, Hawassa, Ethiopia \\ ${ }^{2}$ Department of Botany and Plant Physiology, University of Buea, Buea, Cameroon \\ ${ }^{3}$ Department of Biology, Hawassa University, Hawassa, Ethiopia \\ Correspondence should be addressed to Zerihun Girma; zeru75@yahoo.com
}

Received 26 December 2017; Accepted 21 February 2018; Published 28 March 2018

Academic Editor: Daniel I. Rubenstein

Copyright (c) 2018 Zerihun Girma et al. This is an open access article distributed under the Creative Commons Attribution License, which permits unrestricted use, distribution, and reproduction in any medium, provided the original work is properly cited.

\begin{abstract}
The study is aimed at investigating how livestock and human encroachments affect the population distribution and abundance of mountain nyala and Menelik's bushbuck in Arsi Mountains National Park, Ethiopia. Across four dominant habitat types (Afroalpine, Erica, natural forest, and mixed plantation forest) $5 \times 20\left(100 \mathrm{~m}^{2}\right)$ plot was used to assess populations of the ungulates, wood harvesting, and livestock grazing through counting the fresh scats of both livestock and wild mammals and stumps of trees. There was significant negative correlation between the scat count of mountain nyala and livestock dung scat count during both dry $(R=-0.518, p=0.031)$ and wet $(R=-0.385, p=0.05)$ seasons. However, there was significant negative correlation between the scat count of Menelik's bushbuck and livestock dung scat count only during dry season $(R=-0.491, p=0.047)$. Season (wet versus dry) had significant effect on scat count of mountain nyala, Menelik's bushbuck, and livestock. The study has clearly indicated that livestock outcompeted the endemic ungulates. Furthermore, the result of the study has indicated that tree removal reduced the wildlife habitat quality affecting the populations of wildlife. As a result, there is an urgent need for controlling the free-roaming domestic mammals, wood collection, and other human disturbances.
\end{abstract}

\section{Introduction}

Wildlife habitat degradation, fragmentation, and loss are common phenomena worldwide [1-6]. Habitat degradation, fragmentation, and loss affect the survival of wildlife populations through reducing the amount of available habitats, reducing habitat quality, and creating edge effects [7-9]. Habitat fragmentation creates small metapopulations that are vulnerable to a number of population extermination factors such as inbreeding, predation, disease, and poaching that may lead to direct population extinction $[8,9]$. According to International Union for Conservation of Nature and Natural resources (IUCN) (2016), around 86\% of threatened mammals are at risk due to habitat loss. Wildlife habitat threats are enormous in developing countries where the livelihood of many is highly dependent on subsistence use of natural resources and agriculture $[3,10,11]$.
Both mountain nyala (Tragelaphus buxtoni Lydekker, 1910) and Menelik's bushbuck (Tragelaphus scriptus menelik Neuman, 1902) are sexually dimorphic spiral-horned ungulates endemic to the southeastern highlands and highlands of Ethiopia, respectively [12]. The highest populations of mountain nyala occur in Bale Mountains followed by Arsi Mountains and few occur in the Chercher Mountains [7, 8, 13-15]. The recent global population estimate of mountain nyala is 4094 (95\% confidence intervals: 2506-7135) individuals [16], whereas the population estimate for Menelik's bushbuck is unknown [17]. The populations of both ungulates have been declining over the past decades due to habitat degradation, loss, and fragmentation and lost most of their ranges [15]. According to [17], mountain nyala is currently categorized as an endangered species. Menelik's bushbuck is listed under the least concern category due to its fairly high local abundance [17]. 
Deforestation, fire, encroachment by livestock, and agriculture have been known to be the major driving forces for the degradation, fragmentation, and loss of mountain nyala and Menelik's bushbuck habitat, including protected areas $[6,9,18-21]$. Most scholars agree that the annual deforestation rate in Ethiopia is between 160,000 and 200,000 hectares [22]. The rapid decline in forest cover is attributed to a livelihood heavily dependent on extractive use of forest resources for household fuel consumption, house furniture, and house and fence construction [12]. The daily national average wood consumption in the highlands is estimated to be $2 \mathrm{~kg}$ per capita [12]. In the southeastern (Bale and Arsi) highlands of Ethiopia indiscriminate anthropogenic fire is decades old phenomenon in the heath ecosystem [23]. However, in recent decades it is found to be more intense and widespread causing severe damage to wildlife habitat and the wildlife population [7, 24-26]. The local livestock herders in Bale and Arsi Mountains regularly burn vast stretches of Erica to encourage germination of vascular plants, to destroy livestock pests and habitats of livestock predators, and for fuel wood extraction [24-26].

Similar to other anthropogenic pressures, livestock grazing can have strong impacts on wildlife habitat and overall ecosystem functioning. Livestock grazing has become a common practice in most Ethiopian parks [19, 20, 27]. This has forced the wild herbivores to obtain their forage resources from the remaining poor quality forage $[24,28]$. The abundance of mountain nyala $[4,9,29]$ and Menelik's bushbuck [29] declined with increased number of livestock in Bale Mountains National Park. Reference [8] also pointed out those areas where $50 \%$ of the park has been settled by humans to be avoided by mountain nyala. In addition, studies have revealed that intensive livestock grazing alters the vegetation composition and structure through selective grazing [4, 30]. Livestock grazing and browsing can cause uprooting, trampling, and preying on fruits/seeds that strongly hamper recruitment and understory vegetation regeneration reducing the cover and foraging opportunities of the mountain nyala and Menelik's bushbuck [30]. Studies in Bale Mountain National Parks and adjacent mountains have revealed the effect of deforestation, livestock grazing, fire, and expansion of agriculture adversely affecting the distribution and abundance of mountain nyala and Menelik's bushbuck [4, 79, 20, 31]. Particularly [31], using GIS and remote sensing technology, pointed out that historically the natural range of mountain nyala was far greater than the current range, but shrank due to expansion of agriculture, livestock grazing, and deforestation.

Unlike Bale Mountains National Park, where attempts have been made to investigate the impacts of human and livestock encroachments on the abundance and distribution of mountain nyala and other wildlife $[4,5,19]$, there have not been any detailed studies that investigated the situation in Arsi Mountains National Park. Particularly, due to the fact that Arsi Mountains are less accessible and harbour few populations of both mountain nyala and Menelik's bushbuck than Bale Mountains wildlife studies have been limited. However, the knowledge about the impacts of humans and livestock encroachments into wildlife habitat is a critical issue in wildlife conservation especially in areas where the impact is severe, like Arsi Mountains National Park. Moreover, in the newly (2011) established Arsi Mountains National Park (AMNP), multiple severe anthropogenic threats have been operating together for decades to affect the survival of the mountain nyala and Menelik's bushbuck, whereas Bale Mountains National Park (BMNP) has been under better protection since its establishment as a national park in 1970 [12]. For example, one of the most preferred habitats of both mountain nyala and Menelik's bushbuck, the Afro-montane forest, is almost lost in Arsi, while it is represented by vast area in Bale Mountains [7, 31]. Furthermore, the size of each habitat type in AMNP is more reduced in BMNP. As a result, the situation in BMNP is quite different from the situation in AMNP. To this end, understanding the level of human disturbance in AMNP will provide important input for the preparation of management plan and informed decisionmaking to balance the trade-off between human needs and the wildlife. Therefore, the present study is aimed at investigating how livestock and human encroachments affect the distribution and abundance of mountain nyala and Menelik's bushbuck habitats in Arsi Mountains National Park.

\section{Materials and Methods}

2.1. Study Area. Arsi Mountains National Park is a newly established (2011) national park located in southeastern part of Ethiopia in Oromiya Regional State [32, 33]. The park consists of four fragment blocks that are no longer connected to each other, namely, Dera $\left(13 \mathrm{~km}^{2}\right)$, Chilalo-Galama $\left(792 \mathrm{~km}^{2}\right)$, Kaka $\left(104 \mathrm{~km}^{2}\right)$, and Hunkolo $\left(22 \mathrm{~km}^{2}\right)$ blocks [33]. The three blocks, Chilalo-Galama, Kaka, and Hunkolo, are highland mountain ecosystems characterized by similar biophysical characteristics, once connected to each other before human settlements, deforestation, and agricultural expansion separated the fragments $[20,31]$. The present study area, Galama Mountains (part of Chilalo-Galama block), is situated between 7.48 to $7.88^{\circ} \mathrm{N}$ and 39.27 to $39.51^{\circ} \mathrm{E}$ (Figure 1) and located between the interboundary regions of four Woredas (Districts), namely, Tena, Degeluna-Tijo, Shirka, and Lemu-Bilbilo (Figure 1). The study area is characterized by humid montane climate with bimodal rainfall pattern. The mean annual rainfall ranges from 778.7 to $1089.65 \mathrm{~mm}$ [34]. The study area has a mean monthly maximum temperature of $22.4^{\circ} \mathrm{C}$ and minimum of $11.1^{\circ} \mathrm{C}$ [34]. Currently, the Galama Mountains are characterized by Afro-alpine vegetation at higher altitudes (3600-4008 $\mathrm{m}$ asl), dominant ericaceous vegetation in the middle altitude (3539-3889 $\mathrm{m}$ asl), and remnant Afro-montane (2843-3456 m asl) forest (Tena Woreda) and mixed plantations (3181-3340) (Lemu-Bilbilo and Shirka Woredas) at the lower altitudes [35]. The Galama Mountains have been reported to harbour metapopulations of endemic and endangered large mammals like Tragelaphus buxtoni (mountain nyala) $[7,8,15]$, Canis simensis (Ethiopian wolf) [36], and Tragelaphus scriptus menelik (Menelik's bushbuck) [15]. The four Woredas bordering the Galama blocks are one of the most populous districts in the region, and more than $90 \%$ of the population in each woreda lives in rural areas surrounding the Galama Mountains [35]. The park is 

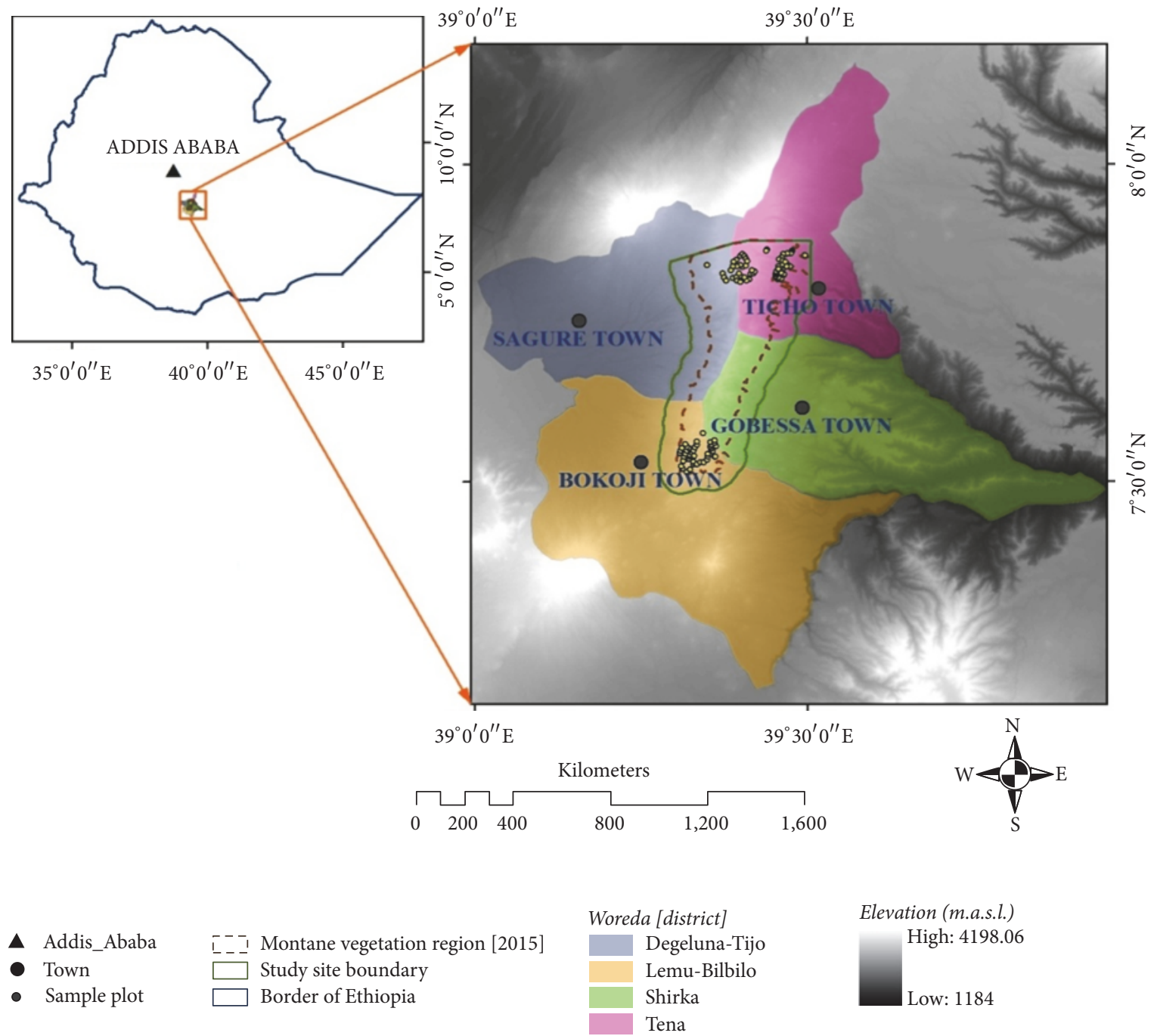

FIGURE 1: Location map of Arsi Mountains National Park (Galama Mountains).

surrounded by agriculture-dominated landscape followed by human settlements often influencing the forest landscape with severe human inhabitations and livestock encroachments $[7,20]$. Wood harvesting, livestock grazing, and fire are common activities in the area for decades that has led to habitat degradation and fragmentation $[7,13,20,37,38]$.

2.2. Sampling Design. To have better insight into the impact of livestock and human encroachments on the abundance and distribution of T. buxtoni and T. s. menelik, a stratified random sampling design across the four dominant habitat types found in the study area (natural forest, mixed plantation forest, Erica shrub lands, and the Afro-alpine) was used. Arc GIS software v10.1 was used to generate random sampling plots [39] across these habitat types. The plots were spaced at least $300 \mathrm{~m}$ apart and the size of each plot was $100-\mathrm{m}^{2}$ plot $(20$ $\times 5 \mathrm{~m}$ ). To minimize edge effect plots were established $200 \mathrm{~m}$ far away from the edge of the forest and main road. Plots were situated lengthwise following the slope of the ground in an attempt representing subtle ecotones and capturing the greatest number of scats. Plots were purposively established on the southern and northern ends of the study area to capture all the four dominant habitat types (Afro-montane natural forest, mixed plantation forest, Erica scrub, and Afroalpine) and areas where the mountain nyala and Menelik's bushbuck cooccurred with the livestock and where tree removal is evident (Figure 1). The approximate area of each habitat type was estimated during the field reconnaissance survey and from the literature [7], the knowledge was used to determine the proportion of sample plots needed to represent each of the four habitat types. Based on this, 104 sampling plots were selected and surveyed: 24 in the natural forest, 9 in the mixed plantation forest, 53 in the Erica, and 18 in the Afro-alpine (Table 1).

2.3. Data Collection. Data were collected during the dry and wet seasons of 2014 and 2015, using a Garmin eTrex Legend Global Positioning System (GPS), navigating to each sampling plot location that was randomly generated in a geographic information system (GIS) using Arc GIS software 
TABle 1: Biophysical characteristics of sampling plots in the Galama block of the Arsi Mountains National Park.

\begin{tabular}{lcccc}
\hline Characteristics & & \multicolumn{3}{c}{ Habitat types } \\
& Afro-alpine & Erica & Natural forest & Mixed plantations \\
\hline Total area (Ha) & 11482 & 25828 & 9722 & 218 \\
Total area sampled (m2) & 1800 & 5300 & 2400 & 900 \\
Number of plots & 18 & 53 & 24 & 9 \\
Number of plots recently burned & 0 & 5 & 0 & 0 \\
Average number of tree stump counts per plot & NE & NE & $4.16 \pm 1.39$ & NE \\
\hline
\end{tabular}

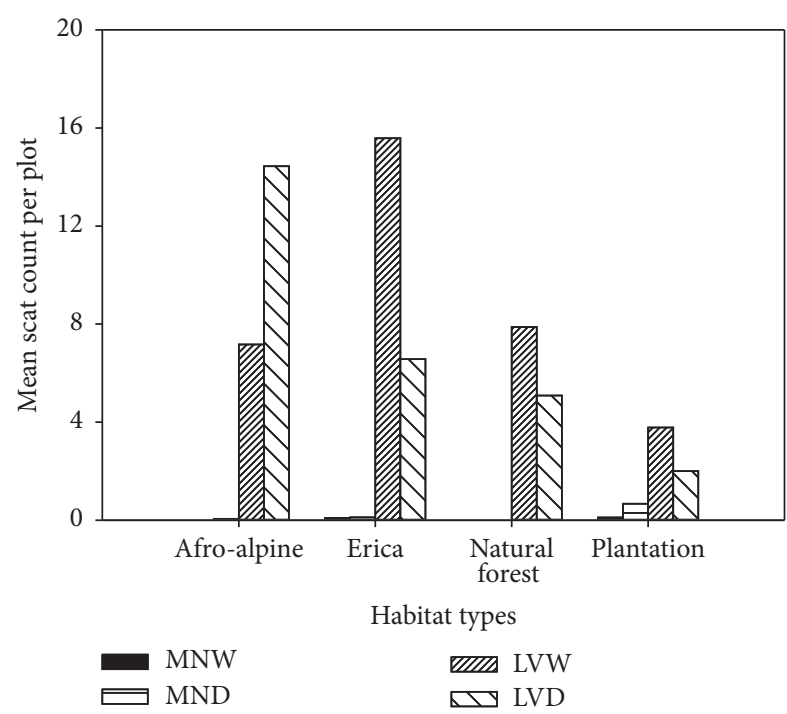

(a)

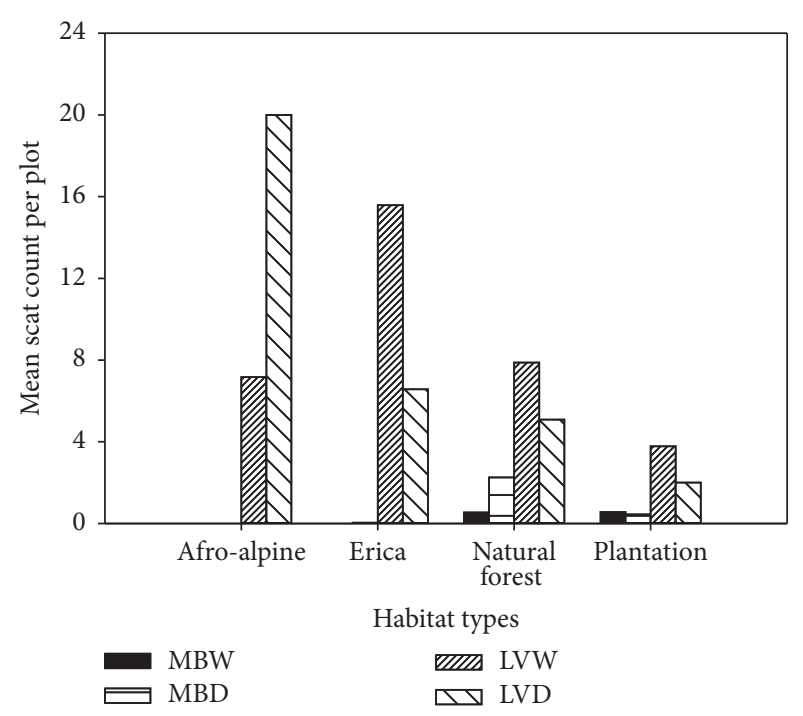

(b)

Figure 2: Mean scat count of mountain nyala (a), Menelik's bushbuck (b), and livestock per plot among dominant habitat types.

v10.1. To correctly navigate to the plots, additional considerations such as having more than 1 coordinate, distance between plots, altitude, slope, vegetation characteristics, and natural marks were used. The number of fresh (intact, green colour) scat piles deposited by mountain nyala, Menelik's bushbuck, and livestock dung and burn history in the 100$\mathrm{m}^{2}$ plot was recorded as a proxy for habitat use during both wet and dry seasons. Behaviourally, both mountain nyala and Menelik's bushbuck deposit pellets grouped together. A scat pile was defined as having 10 or more pellets grouped and this technique was used to avoid scat count overlap. Furthermore, tree stump count (natural forest only) and burn history were recorded in the $24100-\mathrm{m}^{2}$ plots to characterize the disturbance and the correlation with the abundance of mountain nyala and Menelik's bushbuck using scat count as a proxy of abundance. Only recent burns (less than one year, determined in consultation with the park scouts) were considered as burned. Tree stump counts were confined to natural forest habitat type due to the fact that other habitat types did not have trees except exotic planted trees in the mixed plantation habitat type. The two habitat types (Erica and Afro-alpine) do not support the growth of trees ecologically (located at high latitude above tree line $>3500 \mathrm{~m}$ asl). The tree line of Ethiopia is about $3400 \mathrm{~m}$ asl [23]; hence trees do not grow above this altitude. On the other hand, the planation forest contains only stands of exotic tree species that are heavily managed and well protected, hence no stump count.

2.4. Data Analysis. The scat count data of both the wild and domestic mammals and burn history data were analysed per plot using MS Excel software 2010. MINITAB release 17 [40] was used for the computations of all the statistical analysis. Pearson's correlation analysis was carried out to compare the relationship between scat count of mountain nyala and Menelik's bushbuck versus livestock dung count in both dry and wet seasons. Furthermore, Pearson's correlation analysis was carried out to compare the relationship between stump counts of trees versus scat count of Menelik's bushbuck during wet and dry seasons in the natural forest habitat. The nonparametric Kruskal-Wallis test was used to test the difference in the scat counts of mountain nyala, Menelik's bushbuck, and livestock among wet and dry seasons.

\section{Results}

The highest scat count of mountain nyala was recorded in mixed plantation forest during the dry season, while the highest record for Menelik's bushbuck was in the natural forest during the dry season (Figures 2(a) and 2(b)). On the other hand, the highest livestock dung count was recorded 
TABLE 2: Pearson's correlation between mountain nyala and Menelik's bushbuck scat counts versus different disturbance parameters among dominant habitats of Galama Mountains in both dry and wet seasons.

\begin{tabular}{|c|c|c|c|c|c|}
\hline \multirow{2}{*}{ Habitat types } & \multicolumn{5}{|c|}{ Disturbance parameters } \\
\hline & LVDW & LVDD & SCWNF & SCDNF & Number of plots burned \\
\hline \multicolumn{6}{|c|}{$\begin{array}{l}\text { Mixed plantation } \\
\text { forest }\end{array}$} \\
\hline MNSW & $\begin{array}{l}R=-0.827 \\
P=0.054^{*}\end{array}$ & $\mathrm{NV}$ & NA & NA & NA \\
\hline MNSD & NV & $\begin{array}{c}R=-0.901 \\
P=0.051^{*}\end{array}$ & NA & NA & NA \\
\hline MBSW & $\begin{array}{c}R=-0.704 \\
P=0.045^{*}\end{array}$ & NV & NA & NA & NA \\
\hline MBSD & NV & $\begin{array}{c}R=-0.703 \\
P=0.026^{*}\end{array}$ & NA & NA & NA \\
\hline \multicolumn{6}{|l|}{ Natural forest } \\
\hline MBSW & $\begin{array}{c}R=-0.167 \\
P=0.436\end{array}$ & $\mathrm{NV}$ & $\begin{array}{l}R=-0.786 \\
P=0.048^{*}\end{array}$ & NA & NA \\
\hline MBSD & NV & $\begin{array}{l}R=0.011 \\
P=0.961\end{array}$ & $\begin{array}{l}R=-0.526 \\
P=0.038^{*}\end{array}$ & $\begin{array}{c}R=-0.286 \\
P=0.098\end{array}$ & NA \\
\hline \multicolumn{6}{|l|}{ Erica } \\
\hline MNSW & $\begin{array}{c}R=-0.456 \\
P=0.045^{*}\end{array}$ & NV & NA & NA & $\begin{array}{l}R=0.887 \\
P=0.049^{*}\end{array}$ \\
\hline MNSD & NV & $\begin{array}{c}R=-0.517 \\
P=0.078\end{array}$ & NA & NA & $\begin{array}{l}R=0.633 \\
P=0.052^{*}\end{array}$ \\
\hline MBSD & NV & $\begin{array}{c}R=-0.111 \\
P=0.428\end{array}$ & NA & NA & $\begin{array}{l}R=0.209 \\
P=0.280\end{array}$ \\
\hline Afro-alpine & & & & NA & \\
\hline MNSD & $\mathrm{NV}$ & $\begin{array}{l}R=0.840 \\
P=0.001^{*}\end{array}$ & NA & & NA \\
\hline
\end{tabular}

Note. $* *$ indicates that the correlation is significant at the 0.001 level, whereas $*$ indicates that correlation is significant at 0.05 level. MNSW: mountain nyala scat wet, MNSD: mountain nyala scat dry, MBSW: Menelik's bushbuck scat wet, MBSD: Menelik's bushbuck scat dry, LVDW: livestock dung wet, LVDD: livestock dung dry, SCWNF: scat count wet natural forest, SCDNF: scat count dry natural forest, NV: not valid, and NA: not available.

in the Erica habitat in both dry and wet seasons (Figures 2(a) and 2(b)). Anthropogenic burning of Erica scrub was recurrent in the Erica habitat (Table 1).

There was significant negative correlation between the scat count of mountain nyala and livestock dung scat count during both dry $(R=-0.518, p=0.031)$ and wet $(R=$ $-0.385, p=0.05$ ) seasons. However, there was significant negative correlation between the scat count of Menelik's bushbuck and livestock dung scat count only during dry season $(R=-0.491, p=0.047)$. More specifically, there was significant negative correlation between the scat count of mountain nyala and livestock dung scat count in the mixed plantation habitat during both wet $(R=-0.827, p=0.054)$ and dry $(R=-0.901, p=0.051)$ seasons. There was also significant negative correlation between the scat count of mountain nyala and livestock dung scat count during wet $(R=-0.456, p=0.045)$ and dry seasons $(R=-0.840$, $p=0.001)$ in the Erica and Afro-alpine habitats, respectively (Table 2). Similarly, there was significant negative correlation between the scat count of Menelik's bushbuck and livestock dung in the mixed plantation forest during both dry $(R=$ $-0.703, p=0.026)$ and wet $(R=-0.704, p=0.045)$ seasons (Table 2).
There was a significant $(H=23.02, \mathrm{DF}=2, p=0.001)$ difference between the scat count of mountain nyala among wet and dry seasons (Figure 2(a)). Likewise, there was significant $(H=18.11, \mathrm{DF}=6, p=0.006)$ difference between the scat count of Menelik's bushbuck among wet and dry seasons (Figure 2(b)). Furthermore, there was significant $(H=18.11$, $\mathrm{DF}=6, p=0.006)$ difference between the dung count of livestock among dry and wet seasons (Figure 3).

There was also significant negative correlation between scat count of mountain nyala and number of plots burned with the recurrent anthropogenic fire in the Erica habitat during wet $(R=-0.887, p=0.049)$ and $\operatorname{dry}(R=-0.633, p=$ 0.054 ) seasons (Table 2 ). There was also significant negative correlation between Menelik's bushbuck and tree stump count in the natural Afro-montane forest during wet $(R=$ -0.786, $p=048)$ and $\operatorname{dry}(R=-0.526, p=038)$ seasons (Table 2).

\section{Discussion}

Studies elsewhere in Ethiopia have shown that grazing by free-range livestock has strong negative impacts on the populations of mountain nyala and Menelik's bushbuck, their 

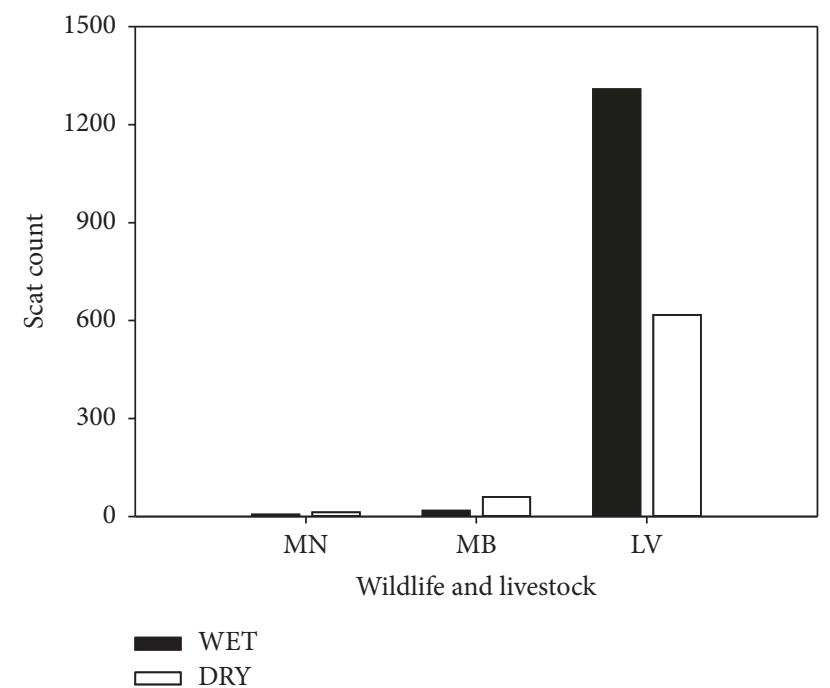

FIGURE 3: Mountain nyala (MN), Menelik's bushbuck (MB), and livestock (LV) scat counts during dry and wet seasons.

habitats, and overall ecosystem function and structure $[4,5$, $7,8,19]$. Livestock have been reported to intensively compete with population of mountain nyala and Menelik's bushbuck for different habitat resources including forage, water sources, and space $[4-6,9,15,19]$.

Particularly, the result of this study has shown that livestock has a negative influence on the population of mountain nyala and Menelik's bushbuck. This could be due to the fact that livestock grazing reduces the forage opportunity of the wild herbivores through direct competition. This could force the mountain nyala and Menelik's bushbuck to consume the less nutritious forage. Furthermore, livestock grazing could also have reduced the cover opportunity for the mountain nyala and Menelik's bushbuck through overbrowsing and removing the herbaceous understory cover. Several studies in BMNP have revealed the same findings (e.g., $[4,7,8,19]$ ). Particularly, livestock grazing has been described as a powerful driver of plant population dynamics and community succession $[4,6,9,19]$ and influences the abundance and distribution of the mountain nyala. A study by [20] also revealed the same findings in Kaka and Hunkolo blocks of AMNP that the number of large wild mammals and small mammals was low in areas where the number of livestock was high.

The high number of livestock during the wet season is due to the decrease in available grazing land in the lower elevations that are instead covered with crops. As a result, livestock shift to higher attitudes especially to the natural forest and Erica for grazing opportunities. During the study period, many temporary huts for herders and their livestock were observed in the upper altitude of the natural forest and lower altitude of the Erica scrub land. By contrast, during the dry season movement to upper altitudes is restricted because harvesting of crops makes land and crop residues available for feeding. Various studies in Bale and Arsi Mountains revealed the same observations [4-6, 19, 20, 28]. In Arsi, the movement of the livestock into the mountains is much worse than BMNP due to the fact that Arsi Mountains are only recently (2011) declared as national park whereas BMNP was established in 1979 [12]. As a result, there have been immense anthropogenic disturbances like deforestation, fire, and livestock grazing that persisted for decades in AMNP [7].

The negative correlation between tree stump counts and the relative abundance of mountain nyala and Menelik's bushbuck could be a consequence of the poor cover and foraging opportunities due to overharvesting of tree species that could be used for cover and forage. About $55 \%$ of the tree species recorded in the natural forest was found to be harvested for different purpose (house and fence construction, household fuel consumption, and household furniture construction) [35]. However, among the tree species grown in the natural forest habitat $60 \%$ were consumed either by mountain nyala or Menelik's bushbuck [35]. Additionally, the regenerating potential of these tree species is lower than the harvest [35]. The extensive livestock grazing in Arsi Mountains National Park could have reduced regeneration of tree species. Particularly, it has been indicated that regeneration of trees like Prunus africana, Syzygium guineense, and Hagenia abyssinica in the nearby Munessa Forest has declined due to excessive grazing/browsing and trampling pressure on young seedlings and saplings by livestock [30]. Most of the trees have been shown to be consumed by mountain nyala in the Munessa Forest [7]. Hence, these anthropogenic disturbances could have caused mountain nyala to avoid the natural forest in the present study area. In addition, the Afro-montane natural forest in Arsi is rudimentary and fragile as compared to the relatively vast extent of the Afro-montane natural forest in BMNP [8, 29, 31]. Hence, mountain nyala could avoid the natural forest due to its small size and poor quality habitat and shifted to the wider Erica habitat. Studies in Bale have indicated that mountain nyala inhabit the natural forest, but tend to avoid areas with poor cover and less food availability such as areas, where grazing by livestock is dominant $[4,8,9$, $19,31]$. In addition, it has also been indicated that Menelik's bushbuck prefers areas with dense cover and food availability, though it is better able to tolerate habitat destruction and modifications than mountain nyala $[20,21]$. Furthermore, behavioural studies of both mountain nyala and Menelik's bushbuck have pointed out that both species are elusive and sensitive to the presence of humans in their home ranges $[21,41,42]$. Consequently the people, accompanying livestock herds, could add pressure by disturbing wild animals and paving the way for poaching. This in turn threatens the survival of the two wild ungulate species.

\section{Conclusion and Recommendations}

The study has clearly indicated that livestock abundance negatively impacts the abundance of mountain nyala and Menelik's bushbuck during both dry and wet season. Season has a significant effect on the distribution of mountain nyala, Menelik's bushbuck, and livestock. The abundance of mountain nyala and Menelik's bushbuck was significantly low in wet season; inversely the livestock number was significantly high in the wet season. The higher abundance of livestock in the wet season in search of better grazing opportunities 
has threatened the survival of the two endemic species. Furthermore, the result of the study has indicated that tree removal in the natural Afro-montane forest negatively affects the abundance of Menelik's bushbuck during both dry and wet season. As a result, there is an urgent need for controlling the free-roaming domestic mammals, wood collection, and other human disturbances. There is a need to incorporate the negative impact of livestock grazing on the survival of the two endemic species and possibly on the entire wildlife resource of the park, in the management plan of the newly established national park. The new management plan of the park should also consider alternative grazing lands for pastoral communities around the park and should have the schemes of controlling exploitation of forest resources.

\section{Conflicts of Interest}

The authors declare that they have no conflicts of interest.

\section{Acknowledgments}

The authors are grateful to International Foundation for Science (IFS) and Murulle Foundation for funding this project. They would like to thank Hawassa University, Wondo Genet College of Forestry and Natural Resources for providing transportations to field sites. European Union, Intra-ACP, Strengthening African Higher Education through Academic Mobility (STREAM) deserves especial acknowledgment for laying the foundation stone of this study. The authors' appreciations go to Oromiya Regional State Forest and Wildlife Enterprise, The Arsi Mountains National Park authority, and the involved District Authorities for granting permission to carry out this study in the park under their respective jurisdictions. Thanks are due to Nicholas Young for helping them in the setup of the plots. They are grateful to all the field assistants and park scouts for their dedication and assistance with fieldwork. Thanks are also due to HabtamuTadesse for preparing the study area map. Our sincere gratitude goes to Dr. Paul Evangelista for soliciting research grant, field materials, and encouragement.

\section{References}

[1] S. L. Pimm and P. Raven, "Extinction by numbers," Nature, vol. 403, no. 6772, pp. 843-845, 2000.

[2] T. M. Brooks, R. A. Mittermeier, C. G. Mittermeier et al., "Habitat loss and extinction in the hotspots of biodiversity," Conservation Biology, vol. 16, no. 4, pp. 909-923, 2002.

[3] T. Wiegand, E. Revilla, and K. A. Moloney, "Effects of habitat loss and fragmentation on population dynamics," Conservation Biology, vol. 19, no. 1, pp. 108-121, 2005.

[4] Y. Mamo and A. Bekele, "Human and livestock encroachments into the habitat of Mountain Nyala (Tragelaphus buxtoni) in the Bale Mountains National Park, Ethiopia," Tropical Ecology, vol. 52, no. 3, pp. 265-273, 2011.

[5] M. Yosef, A. Addisu, and M. Girma, "Social organization in the mountain nyala (Tragelaphus buxtoni) population in the Bale Mountains National Park, Ethiopia," Biodiversity and Conservation, vol. 7, no. 2, pp. 103-111, 2015.
[6] S. A. Tadesse and B. P. Kotler, "Attitudes of local people towards the mountain nyala (Tragelaphus buxtoni) in Munessa, Ethiopia," African Journal of Ecology, vol. 54, no. 4, pp. 488-499, 2016.

[7] P. Evangelista, P. Swartzinski, and R. Waltermire, "A Profile of the Mountain Nyala (Tragelaphus buxtoni, 2007)," http://www .africanindaba@co.za.

[8] A. Atickem, L. E. Loe, Ø. Langangen, E. K. Rueness, A. Bekele, and N. C. Stenseth, "Estimating population size and habitat suitability for mountain nyala in areas with different protection status," Animal Conservation, vol. 14, no. 4, pp. 409-418, 2011.

[9] A. Atickem and L. E. Loe, "Livestock-wildlife conflicts in the Ethiopian highlands: Assessing the dietary and spatial overlap between mountain nyala and cattle," African Journal of Ecology, vol. 52, no. 3, pp. 343-351, 2014.

[10] A. Kidane, "Wildlife management problems in Ethiopia," Walia, vol. $8,1982$.

[11] T. Hundessa, Management Problems of Protected Areas in Ethiopia, World Heritage Fund, Paris, France, 1992.

[12] J. Kingdon, The Kingdon Field Guide to African Mammals, Princeton University Press, New Jersey, USA, 1997.

[13] L. H. Brown, "Mammalia: Observations on the status, habitat and behaviour of the mountain nyala tragelaphus buxtoni in ethiopia," Mammalia, vol. 33, no. 4, pp. 545-597, 1969.

[14] D. W. Yalden and M. J. Largen, "The endemic mammals of Ethiopia," Mammal Review, vol. 22, no. 3-4, pp. 115-150, 1992.

[15] Z. Girma, G. Chuyong, P. Evangelista, and Y. Mamo, "Habitat characterization and preferences of the mountain nyala (Tragelaphus buxtoni, Lydekker 1910) and Menelik's bushbuck (Tragelaphus scriptus meneliki, Neumann 1902) in Arsi Mountains National Park, south-eastern Ethiopia," International Journal of Current Research, vol. 7, pp. 23074-23082, 2015.

[16] A. M. Atickem, Landscape genetics and behavioural ecology of mountain nyala (Tragelaphus buxtoni) in the Southern highlands of Ethiopia [Ph.D. thesis], University of Oslo, Oslo, 2013.

[17] IUCN (International Union for Conservation of Nature and Natural Resources), "IUCN Red List of Threatened Species, Version 2012.2," http://www.iucnredlist.org.

[18] T. Bekele, "Phytosociology and ecology of a humid Afromontane forest on the Central Plateau of Ethiopia," Journal of Vegetation Science, vol. 5, no. 1, pp. 87-98, 1994.

[19] P. A. Stephens, C. A. D'Sa, C. Sillero-Zubiri, and N. LeaderWilliams, "Impact of livestock and settlement on the large mammalian wildlife of Bale Mountains National Park, southern Ethiopia," Biological Conservation, vol. 100, no. 3, pp. 307-322, 2001.

[20] Z. Girma, A. Bekele, and H. Graham, "Large mammals and mountain encroachments on mount Kaka and Hunkolo fragments, southeast Ethiopia," Asian Journal of Applied Sciences, vol. 5, no. 5, pp. 279-289, 2012.

[21] D. Yazezew, Y. Mamo, and A. Bekele, "Population Ecology of Menelik's bushbuck (Tragelaphus scriptus meneliki, Neumann, 1902) From Donkoro Forest Proposed National Park, Northern Ethiopia," International Journal of Ecology and Environmental Science, vol. 37, pp. 1-13, 2011.

[22] Ethiopian Ministry of Agriculture and Rural Development (EMoARD), Ethiopia's agricultural sector policy and investment framework 2010-2020, EMoARD, Addis Ababa, Ethiopia, 2010.

[23] G. Miehe and S. Miehe, Ericaceous forests and heathlands in the Bale Mountains of South Ethiopia-Ecology and mans impact, Stiftung Walderhaltung in Africa, Hamburg, Germany, 1994. 
[24] K. Wesche, G. Miehe, and M. Kaeppell, "The significance of fire for afroalpine ericaceous vegetation," Mountain Research and Development, vol. 20, no. 4, pp. 340-347, 2000.

[25] M. Johansson, T. Rooke, M. Fetene, and A. Granström, "Browser selectivity alters post-fire competition between Erica arborea and E. trimera in the sub-alpine heathlands of Ethiopia," Plant Ecology, vol. 207, no. 1, pp. 149-160, 2010.

[26] M. U. Johansson, M. Fetene, A. Malmer, and A. Granström, "Tending for cattle: Traditional fire management in ethiopian montane heathlands," Ecology and Society, vol. 17, no. 3, 2012.

[27] S. Tedla, "Protected areas management crises in Ethiopia," Journal of Ethiopian Wildlife and Natural History Society, vol. $16,1995$.

[28] S. A. Tadesse and B. P. Kotler, "Habitat use by mountain nyala Tragelaphus buxtoni determined using stem bite diameters at point of browse, bite rates, and time budgets in the Bale Mountains National Park, Ethiopia," Current Zoology, vol. 59, no. 6, pp. 707-717, 2013.

[29] L. Nigatu and M. Tadesse, "An ecological study of the vegetation of the Harenna," SINET: Ethiopian Journal of Science, vol. 12, pp. 63-93, 1989.

[30] D. Teketay, "Human impact on a natural montane forest in southeastern Ethiopia," Mountain Research \& Development, vol. 12, no. 4, pp. 393-400, 1992.

[31] P. H. Evangelista, J. Norman III, L. Berhanu, S. Kumar, and N. Alley, "Predicting habitat suitability for the endemic mountain nyala (Tragelaphus buxtoni) in Ethiopia," Wildlife Research, vol. 35, no. 5, pp. 409-416, 2008.

[32] APEDO/ABRDP, "Arsi Zone Planning and Economic Development Office and Arsi-Bale Rural Development Project," in Atlas of Arsi Zone, APEDO/ABRDP, Asella, Ethiopia, 2004.

[33] OFWI (Oromia Forest and Wildlife Enterprise), "Arsi Mountains National Park," http://www.oromiaforest.gov.

[34] Ethiopian National Meteorological Agency (ENMA), Meteorological Data, ENMA, Addis Ababa, Ethiopia, 2015.

[35] Z. Girma, Habitat use, Diet and conservation of the mountain nyala and Meneliks bushbuck [Ph.D. thesis], University of Buea, Park, 2016.

[36] C. Sillero-Zubiri, Behavioural Ecology of Ethiopian Wolf (Canis simensis), Oxford University, Oxford, UK, 1994.

[37] O. Hedberg, "Vegetation belts of the Eastern Africa," Systematic Botany Tidsk, vol. 45, pp. 140-202, 1951.

[38] J. Malcolm and P. Evangelista, The range and status of the mountain nyala, Ethiopian Wildlife Conservation Department and Oromia Rural Land and Natural Resource Department, Addis Ababa, 2004.

[39] Environmental Systems Research Institute (ESRI), Arc GIS software 10.1, ESRI, California, USA, 2012.

[40] Minitab Inc., Statistical package software Release 17, Minitab Inc. State College, New York, USA, 2013.

[41] B. Refera and A. Bekele, "Population status and structure of mountain nyala in the Bale Mountains National Park, Ethiopia," African Journal of Ecology, vol. 42, no. 1, pp. 1-7, 2004.

[42] Y. Mamo, M. A. Pinard, and A. Bekele, "Demography and dynamics of mountain nyala Tragelaphus buxtoni in the Bale Mountains National Park, Ethiopia," Current Zoology, vol. 56, no. 6, pp. 660-669, 2010. 

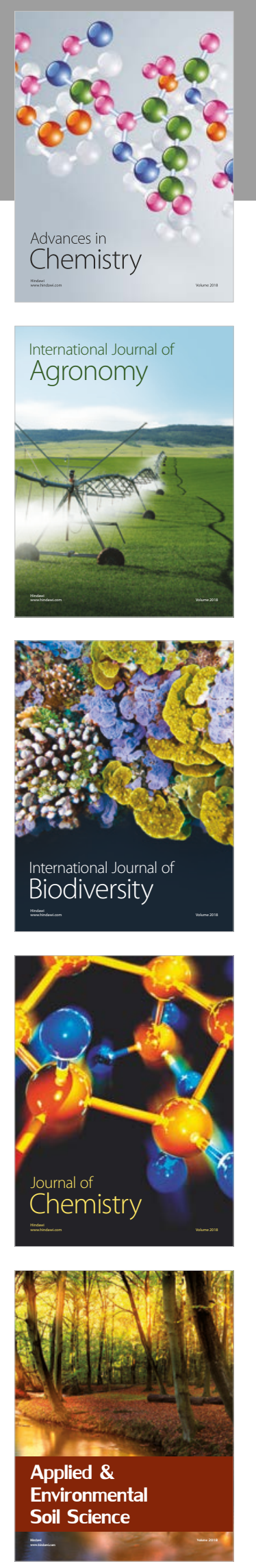

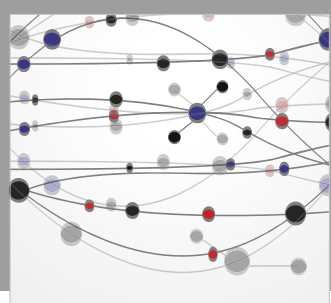

The Scientific World Journal

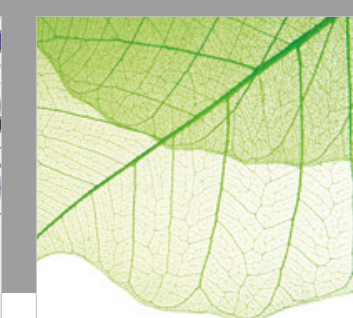

Journal of Botany

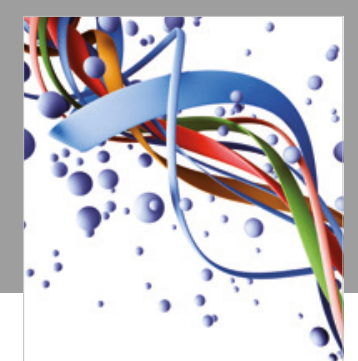

Scientifica

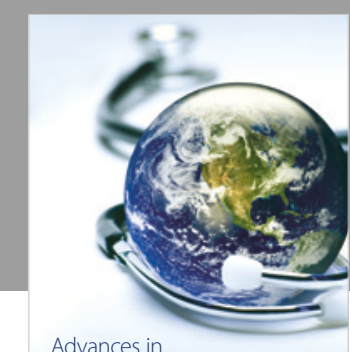

Public Health

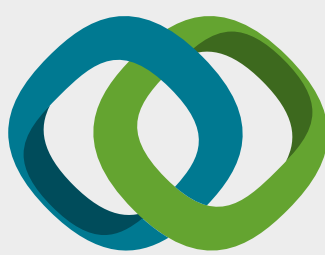

Hindawi

Submit your manuscripts at

www.hindawi.com
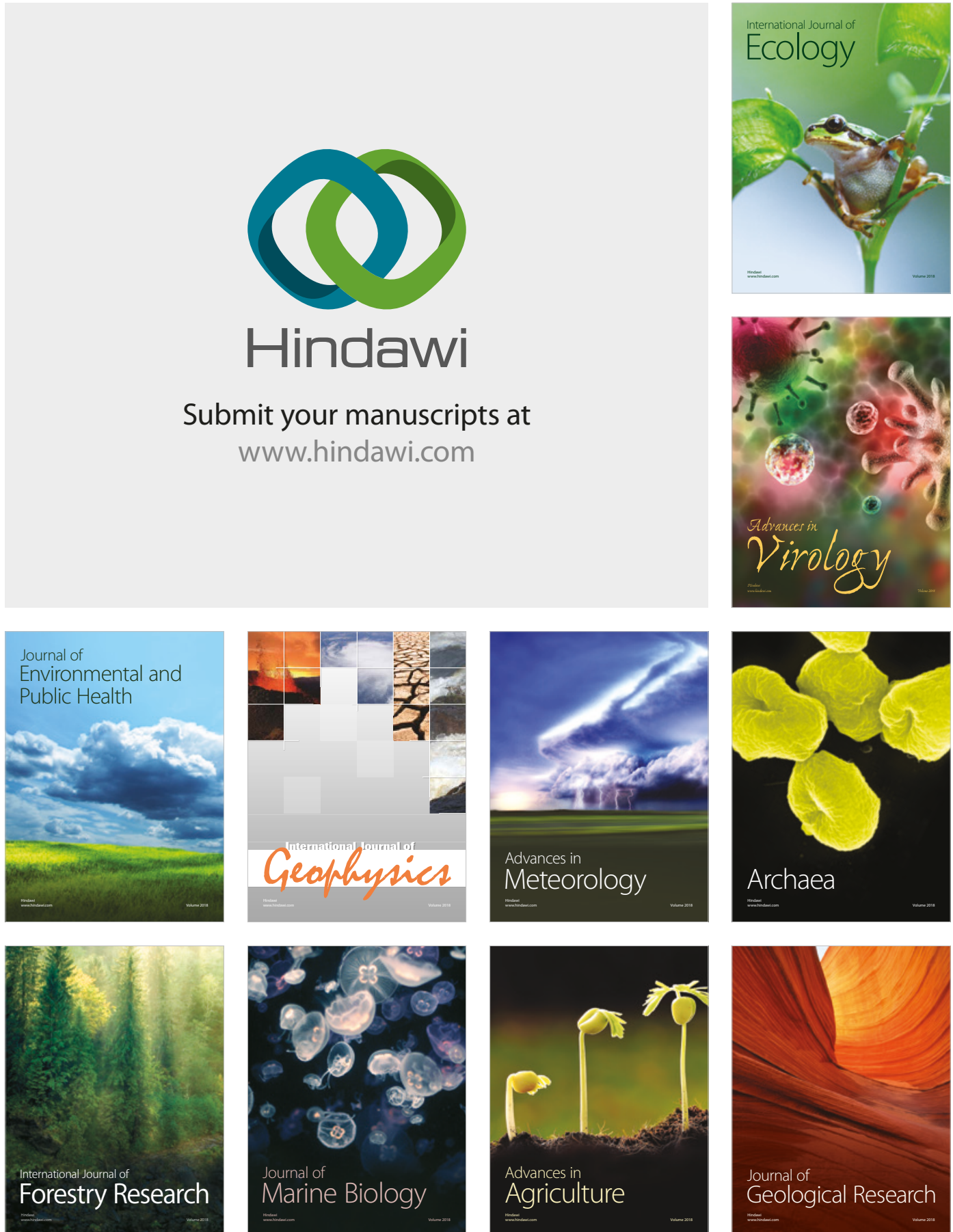

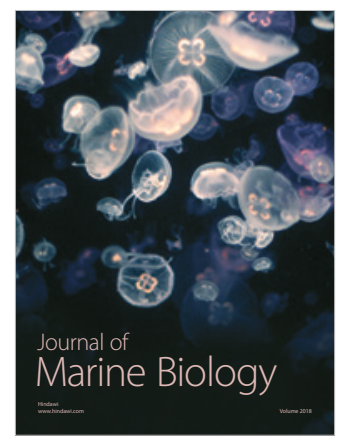

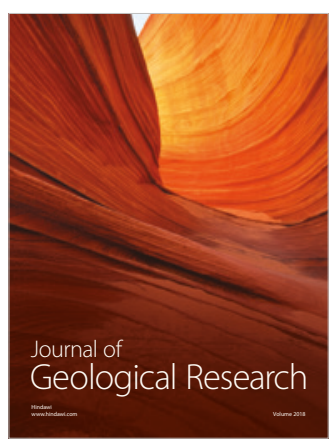

